\title{
When Bioethics Is Too \\ Narrow - The Relevance of \\ Philosophy of Medicine in Medical Education
}

\section{H. ALEXANDER CHEN (D)}

*Author affiliations can be found in the back matter of this article
凹

Levy

Library

Press

\section{ABSTRACT}

What do these terms have in common?

\section{Drapetomania}

Female hysteria

Homosexuality

Sluggish schizophrenia

If you guessed "former medical conditions that were used to pathologize sociallyundesirable persons and their behaviors", you are correct! Drapetomania was described as a mental illness that caused African-American slaves to run away. Female hysteria was first noted in the second millennium BCE and was subsequently used to institutionalize women. Sluggish schizophrenia was used to subjugate political dissidents in the USSR, and homosexuality is one of the more recent "disorders" to undergo depathologization.

These diseases, of course, are now obsolete or exist as behaviors that are widely accepted in western society. So why do they matter? In a sentence - the medical profession exists to treat disease. The corollary - to treat disease, we must first determine what disease is. The historical legacies of medicine are riddled with abuses of human rights stemming from treatment of conditions that were not diseases at all. Today's medical students will go on to discover and classify new diseases, and competency with theories that conceptualize disease and illness are an educational imperative. Clinical bioethics, in particular, often takes for granted terms such as 'disease', 'illness', and 'health'. Knowledge of basic abstract concepts within philosophy of medicine should be foundational, rather than tangential, to medical school humanities curricula.

Naturalistic and normative theories comprise the major types of diseaseconceptualizing theories. Normative theories aim to define disease in terms of value judgments, often taking the form of ' $X$ condition is a disease because it is bad for the person who has it'. Theories differ in their assessment of why the condition is bad (that is, they differ in their value judgements). Naturalistic theories aim to define disease 
without the use of value judgements. This is typically achieved through appeal to deviance from statistical and/or evolutionary function. Each type of theory has its own strengths and limitations, and couching this discussion in terms of historical nosology lends itself to critical examination of pathologization within medicine. Integrating these ideas in medical school curricula will enrich students' understanding of disease, and may mitigate diagnoses that historically harmed patients.

\section{COMPETING INTERESTS}

This publication was funded in part by the Elias E Manuelidis Research Grant, from the Section of the History of Medicine at Yale School of Medicine.

\section{AUTHOR AFFILIATION}

H. Alexander Chen (D) orcid.org/0000-0003-4185-7716

Yale School of Medicine, US
ChMM Journal of Science

and Medicine

DOI: $10.29024 / \mathrm{ijsm} .27$
TO CITE THIS ARTICLE Chen HA. When Bioethics Is Too Narrow - The Relevance of Philosophy of Medicine in Medical Education. ISMMS Journal of Science and Medicine. 2021; 1(1): 2, pp. 1-2. DOI: https://doi. org/10.29024/ijsm.27

Submitted: 15 December 2020 Accepted: 15 December 2020 Published: 20 January 2021

\section{COPYRIGHT:}

(c) 2021 The Author(s). This is an open-access article distributed under the terms of the Creative Commons Attribution 4.0 International License (CC-BY 4.0), which permits unrestricted use, distribution, and reproduction in any medium, provided the original author and source are credited. See http://creativecommons.org/ licenses/by/4.0/.

ISMMS Journal of Science and Medicine is a peer-reviewed open access journal published by Levy Library Press. 